\title{
COVID-19 as a turning point in the fight against disinformation
}

\author{
The COVID-19 pandemic has brought an infodemic of misleading and unreliable information. In response, social \\ media platforms have taken unprecedented steps to moderate content and promote official sources of information, \\ which, combined with new policies and appropriate communication, could help tackle misinformation.
}

\section{Paul Butcher}

E very year on 1 April, Google typically displays an April Fools' joke prominently on its homepage. In 2020, the message was conspicuously absent. Instead, Google provided links to sources of information about the COVID-19 pandemic, such as that of the World Health Organization. With the virus spreading rapidly across the globe, and many countries forced into quarantines and lockdowns, the company recognized that this was not the time for such pranks. But this was not just about avoiding something that might be construed as being in bad taste - it also reflected the complex information environment.

Around the world, the pandemic has been accompanied by an infodemic of misleading, unreliable and even malicious information. This has hindered the efforts of scientists, health professionals and governments to communicate effectively about the virus, how it spreads and how to manage it. And Google's role in this information environment is not a passive one. As the largest online search engine and the owner of YouTube (a platform frequently used to spread conspiracy theories and alarmist content) the company is at the centre of the debate about how technology can facilitate - and limit - the spread of information and disinformation.

\section{The pandemic brings change}

As the virus spread, people turned to online sources for information and guidance. The Reuters Institute for the Study of Journalism has found that online news consumption rose considerably as quarantines began ${ }^{1}$. For example, daily traffic to the BBC News website doubled in March 2020. Social media, already one of the primary venues of social activity for millions of people who could no longer meet and talk in person, also became an important news source: in the UK, a 9\% increase in use of social media for news was reported for under $35 \mathrm{~s}$ between January and April 2020 (Fig. 1).
Smaller increases were also observed for other age groups.

The pandemic - and the confusion around it - provided fertile ground for rumours, disinformation and conspiracy theories to spread, which ranged from the bizarre to the harmful. There were, for example, stories about helicopters disinfecting cities ${ }^{2}$ and about the virus as a bioweapon $^{3}$. In some cases, these stories led to dangerous reactions, such as the spree of arson attacks on $5 \mathrm{G}$ communications infrastructure that were linked to conspiracy theories claiming the virus is caused or exacerbated by $5 \mathrm{G}$ signals ${ }^{4}$.

Debates about online and social media platforms as information gatekeepers have been prominent since at least the political shock of the Brexit referendum in the UK and the presidential election in the US in 2016, where disinformation may have played a role in shifting public attitudes ${ }^{5}$. However, 2020 and the COVID-19 pandemic marked a turning point in information consumption habits and the content moderation policies of social media platforms, as well as the relationship between governments and tech giants.

Social media companies, which have long been reluctant to implement any kind of censorship on their platforms, have taken unprecedented steps to address the issue. Posts that have the potential to cause public harm or unrest have been removed, hidden or restricted, and Twitter even broadened its definition of "harm" to include "content that goes directly against guidance from authoritative sources of global and local public health information"'. COVID-19 has thus demonstrated that the platforms' freedom of speech arguments against regulation or moderation can be overridden when there is a clear, credible threat to public safety - a lesson that should not be forgotten when the current crisis eventually subsides.

Social media platforms also cooperated with health authorities, governments and the

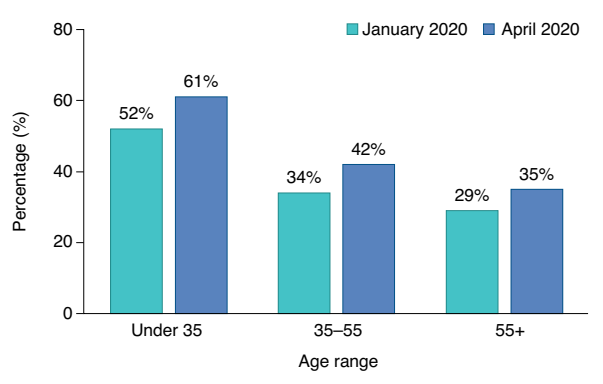

Fig. 1 | Social media as a news source. According to surveys carried out by YouGov for the Reuters Institute for the Study of Journalism in January and April 2020, there has been a clear increase in the use of social media to access news compared with before the pandemic. The graph shows the percentage of people in the UK that had used social media as a source of news in the week before being polled. The largest rise was observed among young people. Data taken from ref. ?

European Commission to promote official information. Google prioritized search results from the World Health Organization or local governments, and Twitter and Facebook displayed prominent messages in users' newsfeeds with links to the pages of the appropriate authorities. These steps also represented a significant departure from previous practice, when online platforms generally resisted any editorial or 'arbiter of truth' role.

The European Commission, following up on its earlier Code of Practice ${ }^{7}$ (a set of voluntary commitments for social media platforms regarding transparency, joint reporting and regular meetings with commissioners), has recently unveiled a new initiative: the European Democracy Action Plan. This initiative will use the lessons of the pandemic to chart a future direction for regulatory responses to disinformation. Rather than dwelling entirely on technical measures, such as algorithmic transparency or cracking down on automated accounts (bots), it focuses on regulating political 


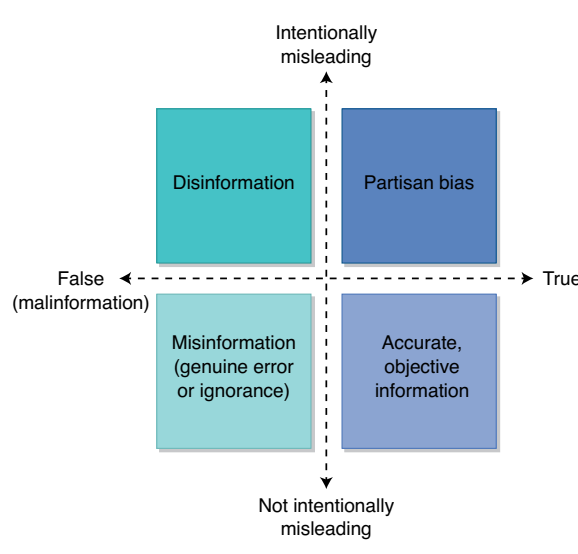

Fig. 2 Disinformation, misinformation and other kinds of information. The term disinformation, which has been suggested as a more accurate alternative to potentially misrepresentative terms such as 'fake news', implies deliberately false content promoted with intent to mislead. It can be contrasted with misinformation, which is inaccurate not out of malicious intent but merely error or ignorance. The distinction serves an important role in the debate about the motivations driving those who produce such content, but in practice both kinds of information pose a threat to effective communication. Malinformation has also been suggested as a term to describe all kinds of harmful content ${ }^{13}$.

advertising, as well as providing support for independent media to ensure they can compete in the online information space. Similar to its efforts to set global standards in data protection (General Data Protection Regulation) and competition policy (the Digital Services Act), the European Commission's attempt to find a sensitive and appropriate solution to disinformation and other challenges facing online public discourse reflects an awareness that these policies are likely to have an impact beyond the European Union's borders.

\section{Informational supply and demand}

Malinformation - a term used to describe all kinds of harmful content (Fig. 2) does not always originate from malicious actors seeking to sow discord. It can also be the result of demand for information that outstrips supply, especially in technical or scientific fields $s^{8}$. The onset of the pandemic saw the rapid dissemination of material that does not appear to have been deliberately misleading, such as rumours relating to treatment and speculation about the origins of the virus. During the early days of the pandemic, in particular, when scientists and healthcare professionals were unable to provide answers, other sources filled the gap. In such an environment, rumours have an appeal even when they are not being actively encouraged.

An urgent topic, such as a health emergency, can also highlight the weaknesses of algorithmically curated information. When more malinformation exists around a particular topic than reliable information, search engines and social media algorithms respond to user input and requests by showing them the available information - even if it is not accurate . Editorial decisions by social media platforms to promote or prioritize official sources may not be able to counteract this effect. Communication channels intended to promote and reward popular content also drive the distribution of malinformation when it is in demand. The 'Plandemic' videos, for example, which depicted COVID-19 as man-made and vaccines as a money-making conspiracy, went viral despite platforms trying to clamp down on their spread. Therefore, social media regulation that insists on more rigorous content moderation, greater transparency for paid promotion and advertising, or other reactive measures may not be effective. The demand itself must be addressed, as must the ability of communicators (including journalists, healthcare professionals and scientists) to respond appropriately and get their message to the right audience.

These problems are not new: underfinanced independent media struggled before the lockdowns; reliable information already had to compete with more attractive sensationalist content, often algorithmically promoted; and people were already spending time in online echo chambers, receiving polarizing information. But the pandemic has exacerbated them. The uncertainty brought by the virus, and the worries created by its health threat and economic impact, have increased people's vulnerability to misleading information at a time when we are more reliant than ever on technology and online channels of information.

\section{Communication is key}

Confusing and at times conflicting government communication contributed to this situation. The lack of coordination between national responses to the pandemic legitimized the view that there exist multiple valid interpretations of the threat posed by the virus, encouraging an anti-lockdown sentiment and the demand for supposed evidence that the threat is overblown. Furthermore, scientific communication often faces challenges in getting its message across to the general public. It cannot always provide conclusive answers, especially regarding research that is still in development such as COVID-19 treatments or vaccines. As a result, it may end up contributing to ambiguity and uncertainty when partial research results are introduced into a politically charged debate ${ }^{10}$. Technical complexity may also be a barrier: one study has found that $44 \%$ of US adults feel they do not know enough about science to understand findings in the news ${ }^{11}$. Communication that attempts to reflect complicated reality and scientific evidence is thus easily passed over in favour of more simplistic but inaccurate messages.

Scientific communication must acknowledge uncertainty, and take into account readers' and viewers' concerns. It should be simple and accessible, and should ideally also be capable of performing well in a social media environment. Methods that may seem unprofessional or excessively light-hearted, such as memes, tend to be successful in gaining viral visibility. The recent use of TikTok by health professionals to spread messages relating to COVID-19 is one example of how this can be done with some success ${ }^{12}$. Thus, those seeking to promote evidence-based communication should take care to ensure that their messages are not only accurate, but catchy too.

\section{Outlook}

Debate about disinformation tends to focus on big events such as election campaigns or the pandemic. In practice, attitudes are shaped over the long term. The next battle for scientists and governments in the fight against COVID-19 and disinformation will be over vaccine hesitancy - another issue that has long been present, but has achieved greater visibility during the pandemic, driven in part by uncertainty and fear of science that is still in development. But the experience of the pandemic so far does provide reasons to be optimistic. Online platforms have started taking more proactive steps, removing harmful content and promoting official sources of information. Digital media literacy and public awareness about misleading information online is also growing. The need for evidence-based policymaking is clearer than ever, and technical expertise is enjoying a renewed prominence among politicians and the public.

As people worldwide have been confined to their homes, the positive impact of online media and technology has also become increasingly apparent. Social media has helped people find support and keep in touch with one another. It has been used effectively to distribute official, accurate information about the pandemic and governmental responses. Contact-tracing apps have helped trace the spread of the 
virus, and people have been able to discuss their symptoms with medical professionals from the safety of their homes. The spread of misinformation online is just one part of this story, and the COVID-19 pandemic may, in the future, be seen as a turning point in the whole relationship between online media, regulators and ordinary citizens.

\section{Paul Butcher (D)}

European Policy Centre (EPC), Brussels, Belgium. 凶e-mail:p.butcher@epc.eu

Published online: 25 January 2021 https://doi.org/10.1038/s41928-020-00532-2
References

1. Newman, N., Fletcher, R., Schulz, A., And1, S. \& Nielsen, R. K. Reuters Institute Digital News Report 2020 https://go.nature. $\mathrm{com} / 2 \mathrm{WcOlBC}$ (Reuters Institute for the Study of Journalism, 2020).

2. Dupuy, B. Helicopters not spraying disinfectant over neighborhoods to stop virus. AP News https://go.nature. com/3pjO24e (23 March 2020).

3. Fisher, M. Why coronavirus conspiracy theories flourish And why it matters. The New York Times https://go.nature. com/3pvW8Hp (8 April 2020).

4. Satariano, A. \& Alba, D. Burning cell towers, out of baseless fear they spread the virus. The New York Times https://go.nature. com/34CcVjM (10 April 2020).

5. Allcott, H. \& Gentzkow, M. J. Econ. Perspect. 31, 211-236 (2017).

6. An update on our continuity strategy during COVID-19. Twitter https://go.nature.com/3qSXtJB (16 March 2020).

7. Code of Practice on Disinformation https://go.nature. com/3mfB0D4 (European Commission, 2018).
8. Shane, T. \& Noel, P. Data Deficits: Why We Need to Monitor the Demand and Supply of Information in Real Time https://go.nature. com/37pXtZN (First Draft, 2020).

9. Golebiewski, M. \& Boyd, D. Data Voids: Where Missing Data Can Easily Be Exploited https://go.nature.com/3akHrSU (Data \& Society, May 2018).

10. Strazewski, L. How science communication is failing during COVID-19. https://go.nature.com/34142Lu (American Medical Association, 27 July 2020)

11. Funk, C., Gottfriend, J. \& Mitchell, A. Science News and Information Today https://go.nature.com/3gTUPIN (Pew Research Center, 20 September 2017).

12. Santoro, H. Doctors and nurses take to TikTok to fight Covid myths. Wired https://go.nature.com/3r5oFFb (6 September 2020).

13. Wardle, C. Information Disorder: 'The Techniques We Saw in 2016 Have Evolved https://go.nature.com/3qMDmwC (First Draft, 2019).

Competing interests

The author declares no competing interests. 